\title{
Sensitive Colorimetric Detection of Interleukin-6 via Lateral Flow Assay Incorporated Silver Amplification Method
}

\author{
Mohammad Rahbar ${ }^{1}$, Yuling $\mathrm{Wu}^{2}$, J. Anand Subramony ${ }^{3 *}$ and Guozhen Liu ${ }^{1,4 *}$ \\ ${ }^{1}$ Graduate School of Biomedical Engineering, The University of New South Wales, Kensington, NSW, Australia, ${ }^{2}$ Integrated \\ Bioanalysis, Clinical Pharmacology and Quantitative Pharmacology, BioPharmaceuticals R\&D, AstraZeneca, Gaithersburg, MD, \\ United States, ${ }^{3}$ Biologics Engineering R\&D, AstraZeneca, Gaithersburg, MD, United States, ${ }^{4}$ School of Life and Health Sciences, \\ The Chinese University of Hong Kong, Shenzhen, China
}

OPEN ACCESS

Edited by: Can Dincer,

University of Freiburg, Germany

Reviewed by: Anatoly V. Zherdev, Bach Institute of Biochemistry, Research Center of Biotechnology (RAS), Russia

Sandeep Surendra Panikar, Washington University Medical

Center, United States

*Correspondence: Guozhen Liu

liuguozhen@cuhk.edu.cn

J. Anand Subramony anand.subramony@ astrazeneca.com

Specialty section: This article was submitted to Biosensors and Biomolecular

Electronics,

a section of the journal Frontiers in Bioengineering and Biotechnology

Received: 16 September 2021 Accepted: 04 November 2021 Published: 26 November 2021

Citation:

Rahbar M, Wu Y, Subramony J and Liu G (2021) Sensitive Colorimetric Detection of Interleukin-6 via Lateral

Flow Assay Incorporated Silver Amplification Method.

Front. Bioeng. Biotechnol. 9:778269.

doi: 10.3389/fbioe.2021.778269
Interleukin-6 (IL-6) is a pro/anti-inflammatory cytokine, the quantitative detection of which has been extensively considered for diagnosis of inflammatory associated diseases. However, there has not yet been a reliable, low-cost, and user-friendly platform developed for point-of-care (POC) detection of IL-6, which will eliminate the conventional costly, time-consuming, and complex assays. In this work, we developed a lateral flow assay for colorimetric detection of IL-6, using anti-IL-6 antibodies conjugated to gold nanoparticles (AuNPs) as the detection probes. Silver amplification technique was incorporated with the newly developed assay in order to enhance the obtained colorimetric signals, allowing sensitive detection of IL-6 in human serum in the desired physiological ranges (i.e., $5-1000 \mathrm{pg} / \mathrm{mL}$ ). A limit of detection of $5 \mathrm{pg} / \mathrm{mL}$ could be achieved for $\mathrm{IL}-6$ detection in serum with the amplification step which was not achievable in the standard assay. The corresponding specificity and reproducibility tests were all preformed to confirm the reliability of this assay for quantitative measurement of IL-6 in a POC manner.

Keywords: point-of-care diagnostics, lateral flow immunoassay, interleukin-6, silver enhancement reagent, paper test strips, colorimetric detection

\section{INTRODUCTION}

Inflammatory diseases include conditions that are characterized by inflammation. Examples include allergy, asthma, autoimmune diseases, hepatitis, inflammatory bowel disease, preperfusion injury, and transplant rejection. While many of these are life threating, diseases such as Sepsis are one the most common and major causes of mortality observed all around the world. Thus, early and efficient diagnosis of such health disorders are crucial for higher survival rates of patients including the onset of worsening inflammatory conditions using biomarkers or assays. There have been numerous biomarkers reported in the literature for inflammatory signals, the concentration of which in body fluids is correlated with conditions. Cytokines are one of these protein biomarkers which are present in different biological samples such as serum, blood, saliva, and sweat, representing high correlations with inflammation, especially when they are in abnormal levels (Seruga et al., 2008; Kumari et al., 2016; Kany et al., 2019). Cytokine storm is one type of life-threatening systemic inflammatory

Abbreviations: $\mathrm{CV}$, coefficient variance; SD, standard deviation 
syndromes resulting in elevated levels of circulating cytokines. The cytokine storm could significantly increase the mortality and morbidity for the current SARS-CoV-2 infection. (Han et al., 2020; Ragab et al., 20202020). Thus, detection and monitoring of these biomarkers can be useful for diagnosis of these diseases. The current laboratory-based testings of cytokines are extremely timeconsuming, involves batch processing of samples, and inefficient, thereby delaying the timely diagnosis process, which can consequently lead to higher risks of death in some cases. Therefore, sensor technologies, especially the point-of-care diagnostic tools have gained extensive attention in order to provide more rapid and robust platforms for detection of the corresponding biomarkers (Stenken and Poschenrieder, 2015; Liu et al., 2021a; Liu et al., 2021b).

Interleukin 6 (IL-6) is a pro/anti-inflammatory cytokine, secreted by immune system cells, which has been extensively considered as a biomarker for diagnosis of inflammation related diseases. IL-6 protein consists of 184 amino acids and has molecular weight of $26 \mathrm{kDa}$. IL- 6 is also a significant element in other physiological disfunctions such as activity of cancer cells. In addition, there have been some interesting reports demonstrating a significant association between inflammation and cancer, resulting from high IL-6 levels in the cancer or disease affected environments (Tanaka et al., 2014). In healthy adults the level of IL- 6 is normally in the range of $5-25 \mathrm{pg} / \mathrm{mL}$, whereas higher levels (e.g., up to $1,000 \mathrm{pg} / \mathrm{mL}$ ) of IL-6 in serum or blood can be associated with the abnormal physical conditions including sepsis or cancer. Our study shows IL-6 level increased more than 5 times in a mice model with Parkinson's disease by comparing with a control mice group. (Shen et al., 2020). It has been reported several times that IL-6 level above $500 \mathrm{pg} / \mathrm{mL}$ can be extremely vital, leading to death in many cases. Since IL-6 is present in very low levels (i.e., pg/mL ranges) in extracellular environment, sensitive, rapid, and accurate detection of IL-6 protein can be challenging (Liu et al., 2021a). Another key indication associated with excess cytokines is called cytokine release syndrome (CRS), an acute systemic inflammatory syndrome characterized by fever that could be due to after treatment effects with certain types of immunotherapy, such as monoclonal antibodies and CAR-T cells. IL-6 seems to hold a key role in CRS pathophysiology since highly elevated IL-6 levels are seen in patients with CRS. In essence, cytokine release syndrome is caused by a large, rapid release of cytokines into the blood from immune cells affected by the immunotherapy. Conventional batch process of cytokine assays such as enzyme-linked immunosorbent assay (ELISA) cannot measure CRS and its onset in real time leading to multiple complications for patients. The non-real time measurement also does not allow adaptive therapy to patients on time.

There have been various platforms developed for quantitative detection of IL-6, and ELISA can be regarded as the most conventional and standard technique in this regard (Liu et al., 2017; Qi et al., 2017; Russell et al., 2019). However, the available conventional methods rely on expensive or bulky instruments, trained personnel, complex and time-consuming assays, which make them unsuitable for point-of-care (POC) detection of this biomarker. Therefore, development of a viable platform for POC quantitative determination of IL- 6 will be highly advantages for early diagnosis of disease states and real time management of patients.

Lateral flow immunoassays (LFAs), have been very well developed and established for a wide variety of applications including clinical diagnostics, food, and water samples testings, and environmental monitoring. LFAs offers some unique advantages such as simplicity, user-friendliness, low-cost, and easy fabrication process, which make them ideal platforms for POC testings. A standard LFA includes a reporter probe capable of interacting with the target analyte followed by a secondary interaction at the test zone (T-line) on the nitrocellulose membrane, indicating the assay signal (Wang et al., 2016; Huang et al., 2020a; Shirshahi and Liu, 2021). Different types of LFAs were developed for detection of IL-6 (Wang et al., 2019; Huang et al., 2020b; Ruppert et al., 2020). A doubled-antibody based LFAs was developed using europium nanoparticles as the fluorescence signal read-out with a wide linear range $(2-500 \mathrm{pg} /$ $\mathrm{mL}$ ) and a good sensitivity $(0.37 \mathrm{pg} / \mathrm{mL})$ (Huang et al., 2020b). Quantum dots were also used as the fluorescence probe in LFA for detection of IL-6 with a sensitivity is $0-20 \mathrm{nmol} / \mathrm{L}$ (Ruppert et al., 2020). A surface-enhanced Raman scattering (SERS)-based lateral flow assay (LFA) is developed for the quantitative analysis of IL-6 with a linear range from $1 \mathrm{pg} / \mathrm{mL}$ to $1 \mu \mathrm{g} / \mathrm{mL}$, and the sensitivity of IL-6 in whole blood is 5 pg/mL (Wang et al., 2019). Even though, there have been so many different types of colorimetric, fluorometric or SERS labels used as a reporter in LFAs, gold nanoparticles (AuNPs) have gained high popularity in this regard due to multiple features such as easy preparation, high affinity for the detection antibodies, and the possibility for nakedeye colorimetric detection. However, when it comes to highly sensitive quantitative analysis of some biomarkers in low abundance such as cytokines, AuNPs are not fully capable of covering the desired demand of sensitive detections (Bahadir and Sezgintürk, 2016; Borse et al., 2020). Nevertheless, several signal amplification techniques have been developed in order to compensate the mentioned weakness, allowing sensitive colorimetric determination of different analytes via AuNPbased LFAs. Silver amplification is one of those methods, which is based on nucleation of silver upon gold surface at the test or control lines of LFA strips, enhancing the intensity of the obtained colorimetric signal (Anfossi et al., 2013; Bishop et al., 2019). Silver enhancement technique has been reported in several studies as a simple and efficient method to achieve high sensitivities in LFAs. Rodríguez et al. investigated different approaches to perform silver enhancement in LFAs in order to find out the most optimal one to detect prostatespecific antigen (PSA). They demonstrated that with the silver enhancement a 3fold sensitivity improvement can be achieved for detection of PSA at levels as low as $0.1 \mathrm{ng} / \mathrm{mL}$ (Rodríguez et al., 2016). In another work, silver enhancement was utilized to develop a highly sensitive LFA for detection of R. solanacearum as a dangerous pathogen in agricultural crops and a 10-fold improvement (LOD $200 \mathrm{CFU} / \mathrm{mL}$ ) in sensitivity was observed (Panferov et al., 2016). In a similar work, a highly-sensitive LFA incorporating silver enhancement was developed for rapid detection of potato leafroll 
virus (PLRV), where the sensitivity (detection limit $0.2 \mathrm{ng} / \mathrm{mL}$ ) was improved as a 15-fold compared to conventional LFA (Panferov et al., 2018). The applicability of silver enhancement was also demonstrated for competitive lateral flow assays as well as regular sandwich assays, where the concertation of ochratoxin A (OTA) was measured in beverages with a 10-fold improvement in sensitivity (Ye and Xia, 2018). This work presents development of a paper-based lateral flow assay (LFA) for rapid, low-cost, and user-friendly quantitative determination of IL-6 in the biological samples in a POC manner. This assay uses gold nanoparticles as the colorimetric recognition tags which are conjugated with the specific IL-6 detection antibodies. Since the target detection limit for IL-6 is extremely low (i.e., in $\mathrm{pg} / \mathrm{mL}$ range), a signal amplification method is incorporated with this colorimetric assay in order to reach the desired sensitivities. Herein, silver amplification technique has been used as a simple, low-cost, and viable amplification approach to enhance the color intensity of the obtained colorimetric signals for IL- 6 detection via the LFA strips. Despite of the demanding sensitivities for IL-6 detection, silver amplification successfully allowed highly sensitive quantitative measurement of IL-6 in both Phosphate buffer saline (PBS) and serum samples with a limit of detection (LOD) as low as 1 and $5 \mathrm{pg} / \mathrm{mL}$, respectively. The specificity and reproducibility of the assay are investigated by performing the corresponding tests in human serum samples in order to further approve the viability and reliability of the developed assay for facile and sensitive detection of IL-6.

\section{EXPERIMENTAL SECTION}

\section{Materials}

Human IL-6 monoclonal antibody (MAB206), biotinylated polyclonal antibody (BAF206), and mouse IgG (AF007) antibody, along with recombinant human IL-6 protein (206IL) were all supplied from R\&D Systems (Minneapolis, United States). Other recombinant human cytokines including IFN- $\gamma$, IL-2, IL-10, and IL- $1 \beta$ were also all purchased from R\&D Systems and used in the specificity tests. PBS (0.01 M, pH 7.4), streptavidin, sucrose, citric acid, boric acid, Tween-20, Tris, sodium tetraborate, bovine serum albumin (BSA), silver nitrate, sodium azide, hydroquinone, and human serum were purchased from Sigma-Aldrich (Castle Hill, NSW, Australia). Glass fiber sample pad (SB06), absorbent pad, nitrocellulose membrane, and backing pad were purchased from Shanghai Kinbio Tech. Gold nanoparticles (AuNPs, $60 \mathrm{~nm}$ ) were acquired from Ted Pella, Inc. (Redding, CA, United States). Water was treated with a Millipore (Bedford, MA, United States) Milli-Q water purification system and was used throughout.

\section{Equipment}

A guillotine strip cutter (ZQ 2002), a XYZ dispenser (HM3035), and a vacuum drying oven (PH050A) were all supplied from Kinbio Tech. Co., Ltd. (Shanghai, China) and implemented throughout for fabrication of LFAs. The quantitative image analysis was carried out using a standard LFA reader $(A x-2 x$,
Axxin, Victoria, Australia). Meso Scale Discovery (MSD) human IL-6 kit (Meso Scale Diagnostics, LLC) was supplied from BioStrategy Pty Ltd., Australia and used to validate the measured IL6 concentrations in the tested serum samples.

\section{Conjugation of Interleukin 6 Antibodies With Gold Nanoparticles}

Initially, $1 \mathrm{~mL}$ of the colloidal gold solution was taken and its media (i.e., citrate buffer) was replaced by sodium borate buffer $(2 \mathrm{mM}, \mathrm{pH}=8.5)$ via centrifugation at $7,000 \mathrm{rpm}$, for $10 \mathrm{~min}$. Then, $5 \mu \mathrm{L}$ of IL- 6 human monoclonal antibody $(0.2 \mathrm{mg} / \mathrm{mL})$ was added into the AuNP solution and incubated for $1 \mathrm{~h}$ at room temperature (RT) with gentle agitation. Afterward, 1\% w/v BSA was added into the conjugate solution as a blocking agent and incubation was carried out for another $30 \mathrm{~min}$ at RT. Finally, the solution was centrifuged $(7,000 \mathrm{rpm}$ for $10 \mathrm{~min})$ and the supernatant was discarded and the acquired pellets were redispersed in the storage buffer (Tris-HCL $10 \mathrm{mM}$ and $\mathrm{pH}=$ 8.2 containing BSA $1 \% \mathrm{w} / \mathrm{v}$, Tween $-201 \% \mathrm{v} / \mathrm{v}$, sucrose $5 \% \mathrm{w} / \mathrm{v}$, and sodium azide $0.01 \% \mathrm{w} / \mathrm{v})$.

\section{Preparation of Lateral Flow Immunoassays Strips}

The nitrocellulose membrane $(300 \times 25 \mathrm{~mm})$ was attached to a plastic backing pad in order to provide the required support for the fragile NC membrane. The supported NC membrane was placed on the dispenser and the corresponding reagents were dispensed upon the $\mathrm{T}$-line and $\mathrm{C}$-line zones. The $\mathrm{T}$-line reagent solution comprised of the biotinylated polyclonal human IL-6 antibody $(0.2 \mathrm{mg} / \mathrm{mL})$ and streptavidin $(1 \mathrm{mg} / \mathrm{mL})$ at a $1: 1 \mathrm{mix}$ ratio, which was preliminary incubated at RT for $1 \mathrm{~h}$. Goat antimouse IgG antibody $(0.5 \mathrm{mg} / \mathrm{mL})$ was directly dispensed at the C-line zone. Dispensing was performed with defined setting parameters including a dispensing volume of $0.3 \mu \mathrm{L} / \mathrm{cm}$ and speed of $100 \mathrm{~mm} / \mathrm{s}$. After dispensing, the $\mathrm{NC}$ membrane was dried in a vacuum oven at $37^{\circ} \mathrm{C}$ for $2 \mathrm{~h}$. Meanwhile, the sample pad $(300 \times 25 \mathrm{~mm})$ was treated with the treatment buffer $(\mathrm{PBS}$ $\mathrm{pH}=7.4$ containing BSA $1 \% \mathrm{w} / \mathrm{v}$, Tween-20 0.25\% v/v, sucrose $2 \%)$ and dried at $37^{\circ} \mathrm{C}$ for $2 \mathrm{~h}$. Finally, the sample pad and absorbent pad $(300 \times 25 \mathrm{~mm})$ were attached to the backing pad, overlapping the NC membrane with a $2 \mathrm{~mm}$ margin. The complete LFA strip was then cut into individual strips $(30 \times$ $5 \mathrm{~mm}$ ) for further use.

\section{Lateral Flow Immunoassay Protocol}

IL-6 standard solutions were prepared by diluting a stock solution $(100 \mu \mathrm{g} / \mathrm{mL})$ of IL-6 in sample buffer (PBS with BSA $0.1 \% \mathrm{w} / \mathrm{v}$ ). The volume of used Au-antibody conjugate was optimized in order to find out the least amount of required conjugate while generating the highest assay sensitivity. The standard LFA (i.e., no amplification) was performed by adding $5 \mu \mathrm{L}$ of $\mathrm{Au}$ conjugate into $65 \mu \mathrm{L}$ of IL- 6 sample, followed by incubation at RT for $5 \mathrm{~min}$. Afterwards, the sample was loaded into the sample pad of paper strips and then the signal readout was carried out after $15 \mathrm{~min}$ using the Axxin reader. Basically, the presented IL-6 LFA is a 


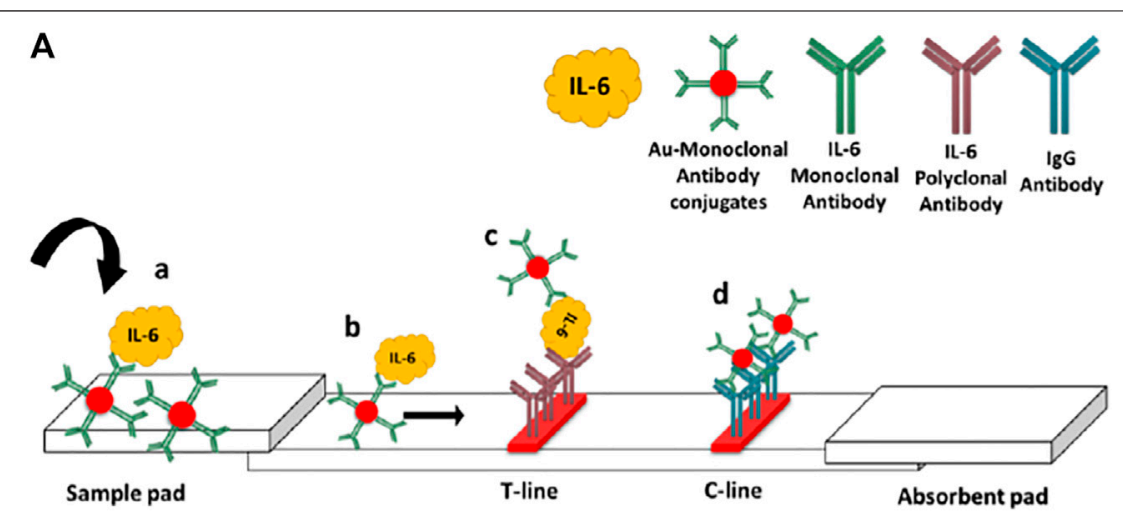

B

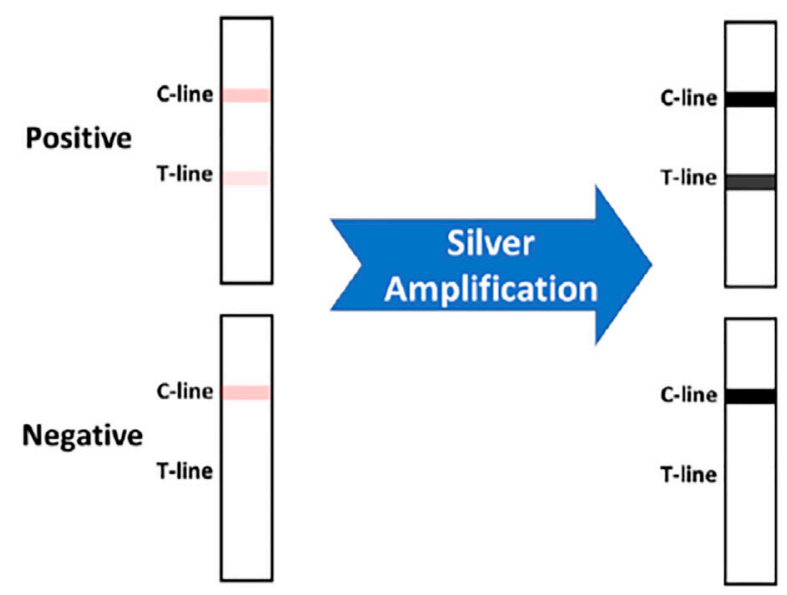

SCHEME 1 | (A) standard IL-6 assay principle: 1) IL-6 analyte will bind with the monoclonal antibody conjugated on AuNPs. 2) The IL-6-conjugate complex will move toward the T and C zones. 3) The formed complex will be captured at the T-line by immobilized IL-6 polyclonal antibody. 4) Free excess conjugates will travel further along the strip until they reach the C-line zone and are captured by the anti-lgG antibody. (B) Effect of silver amplification on the obtained colorimetric signals upon the paper strips.

sandwich immunoassay, implementing AuNPs-antibody conjugates as the colorimetric signalling tags. As shown in Scheme 1A, the IL-6-Au-anti-IL-6 antibody conjugate complex will be loaded into the sample pad of strips which will then move toward the $\mathrm{T}$-line and $\mathrm{C}$-line zones. At the T-line, the complex will be captured by the immobilized polyclonal anti-IL-6 antibody. The excess of conjugates will move even further, where they are captured by the IgG antibody present at the C-line. The appearance of two red lines indicates a positive response. However, if there is no IL-6 analyte present in the introduced sample (i.e., no complex), there will not be any color band formed at the T-line, indicating a negative response.

\section{Silver Enhancement Procedure}

After performing the standard assay (as described above), the silver amplification was applied on the strips in order to enhance the generated colorimetric signals. Before loading the enhancement solution, the absorbent pads of paper strips were dried up by tissue papers (sucking up the accumulated solution) in order to recover their absorption capacity, which was obviously diminished through the standard assay. The silver enhancement solution was prepared freshly by mixing a $1: 1$ ratio of silver nitrate $(0.5 \% \mathrm{w} / \mathrm{v}$ in water) and hydroquinone $(3 \% \mathrm{w} / \mathrm{v}$ in $0.5 \mathrm{M}$ citrate buffer, $\mathrm{pH}=4.0)$. $65 \mu \mathrm{L}$ of the enhancement solution was introduced into the sample pad of strips and then strips were

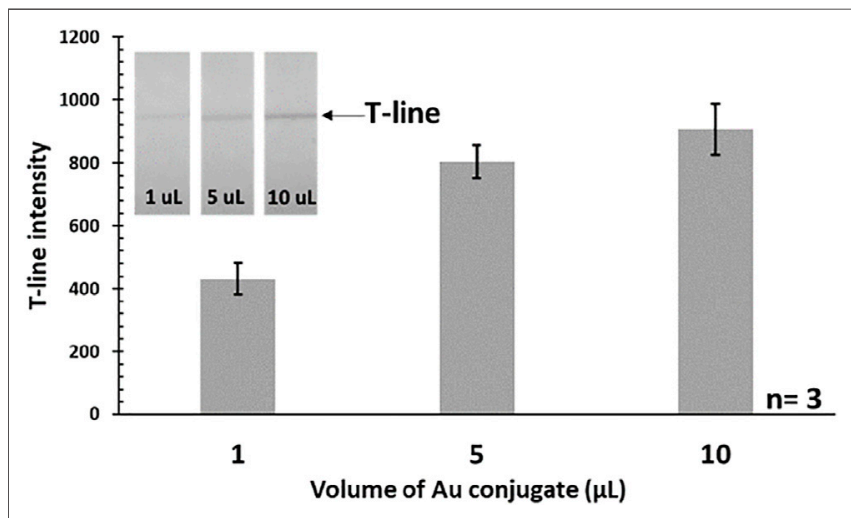

FIGURE 1 | Effect of the used Au-antibody conjugate's volume on the T-line intensity ( $\mathrm{IL}-6=100 \mathrm{pg} / \mathrm{mL})$. Actual photograph of paper strips is shown in the inset. 


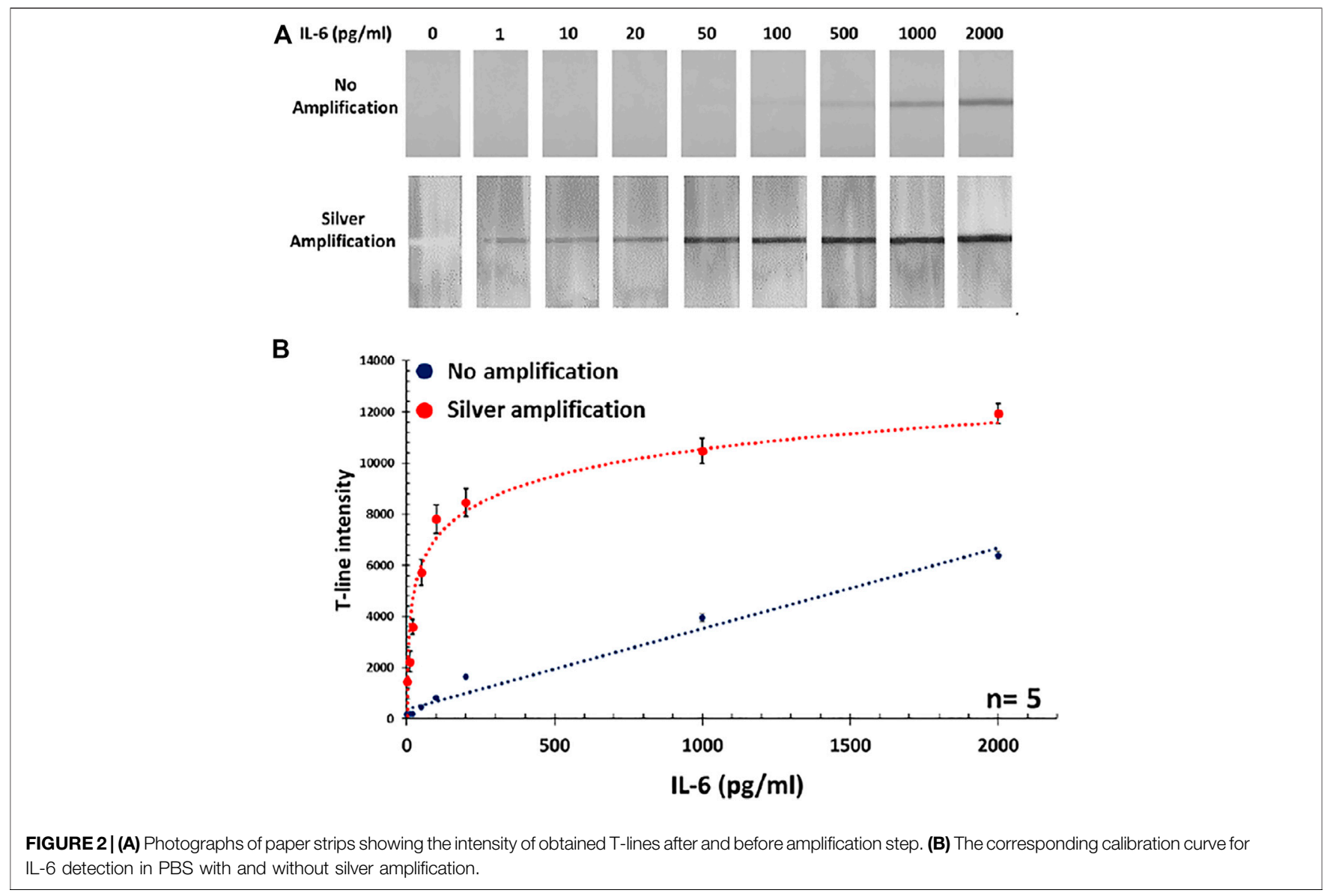

immediately transferred into a dark place for silver enhancement process. Subsequently, the amplified signals were measured after $15 \mathrm{~min}$. In the case of $100 \%$ human serum sample, the assay reading time was $30 \mathrm{~min}$. The working principle of silver amplification is shown in Scheme 1B. Herein, the intensity of obtained color bands (colorimetric signals) in the standard assay will be enhanced through the amplification process.

\section{RESULTS AND DISCUSSION}

\section{Optimization of Au-Antibody Conjugate's Volume}

Initially, the volume of Au conjugate was optimized in order to find out the minimum amount of conjugate required to run the assay, while providing the desired sensitivity. Three different volumes $(1,5$, and $10 \mu \mathrm{L})$ of conjugates were used to run the assay with constant concentration (i.e., $100 \mathrm{pg} / \mathrm{mL}$ ) of standard target IL- 6 analyte. Based on our studies, a $5 \mu \mathrm{L}$ volume of conjugate was found to be sufficient for creating a visible T-line. Using higher volumes (e.g., $10 \mu \mathrm{L}$ ) would be redundant as it did not make a significant difference on the obtained signal at the T-line. On the other hand, lower amounts (e.g., $1 \mu \mathrm{L}$ ) do not produce signals with enough intensity. The optimization results are shown in Figure 1, depicting the correlation between the conjugate volume and T-line color intensity (i.e., the target signal). As a result, $5 \mu \mathrm{L}$ of Au conjugate was used throughout as the optimum amount for the corresponding assays.

\section{Calibration Curve With and Without Amplification}

After finding the optimum volume of $\mathrm{Au}$ conjugate, the calibration curve was obtained using standard IL-6 samples $(0-2000 \mathrm{pg} / \mathrm{mL})$ in PBS. It was observed that below the concentration of $50 \mathrm{pg} / \mathrm{mL}$, there was no visible color band formed at the T-line, so this was considered as the detection limit of the standard assay. Therefore, the standard assay did not provide the required sensitivity (i.e., $10 \mathrm{pg} / \mathrm{mL}$ ) and a signal amplification step was necessary in order to reach the target detection limit. Herein, silver amplification technique, as a wellestablished colorimetric signal amplification method in LFAs, was implemented to resolve this issue. After applying amplification, the intensity of color bands was significantly enhanced and strong signals could be achieved as it was easily visible by the naked eye even at low concentrations below $50 \mathrm{pg} /$ $\mathrm{mL}$. The actual photographs of the paper strips before and after 


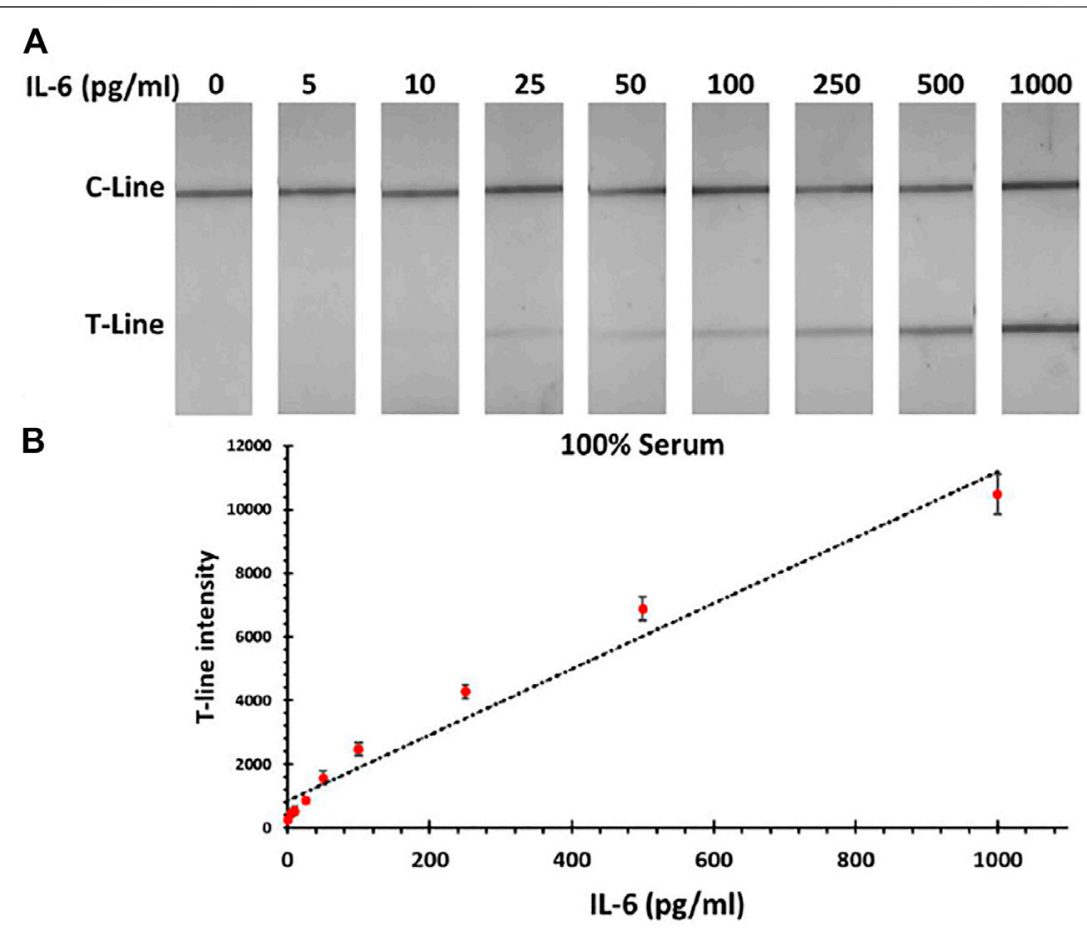

FIGURE 3 | (A) Photographs of LFA strips for detection of IL-6 in human serum samples after applying the silver amplification technique. (B) Corresponding calibration curve for IL-6 detection in serum sample.

amplification are presented in Figure 2A, comparing the intensity of generated color bands at the T-lines. This resulted in the obtained LOD (i.e., in standard assay) being considerably improved down to $1 \mathrm{pg} / \mathrm{mL}$ which was even better than what was required for IL- 6 detection. The acquired calibration curve for detection of IL-6 in PBS, with and without amplification is shown in Figure 2B.

\section{Interleukin 6 Lateral Flow Immunoassay in Human Serum}

After establishing the IL-6 LFA in PBS, the performance of assay was tested in $100 \%$ serum samples spiked with IL-6 protein $(5-1,000 \mathrm{pg} / \mathrm{mL})$. As expected, the serum matrix reduced the obtained signal intensity, which consequently impacted the LOD of the standard assay by increasing it up to $200 \mathrm{pg} / \mathrm{mL}$ (vs $50 \mathrm{pg} / \mathrm{mL}$ for PBS). However, taking advantage of the silver amplification, the IL- 6 detection in the required analytical range could be still achieved by having a LOD of $5 \mathrm{pg} / \mathrm{mL}$. These results indicate that silver amplification is a necessity in order to achieve the required sensitivity in the colorimetric IL-6 LFA assay. Photographs of paper strips along with the corresponding calibration curve for IL-6 detection in serum samples are shown in Figure 3. In order to validate the obtained results, MSD system was used in parallel to measure the concentration of IL- 6 in serum samples, which illustrated a good agreement with the developed IL-6 LFA (within 10\% error).

\section{Specificity Tests}

The specificity test was performed by preparing standard samples $(1,000 \mathrm{pg} / \mathrm{mL})$ of different human cytokines (IFN- $\gamma$, IL- 2, IL-10, and IL-1 $\beta$ ) in serum and then running the assay for each individual sample. It was observed the assay only responds to the target IL-6 sample, while there was no significant signal obtained for other tested cytokine samples, confirming the high specificity of the developed assay. Results regarding these specificity tests are shown in Figure 4A. The specificity test was also further evaluated by running the assay for IL-6 samples $(100 \mathrm{pg} / \mathrm{mL})$ containing excess amount $(1,000 \mathrm{pg} / \mathrm{mL})$ of other individual cytokines as potential interferences. Results showed that the presence of other cytokines (even at a level of ten times higher than the target IL-6 analyte) does not affect the performance of the assay as no interference was recorded. In other words, the assay is totally selective for the target IL-6 analyte. The assay response in these specificity tests is presented in Figure $\mathbf{4 B}$, showing the almost similar signal intensities $(\mathrm{CV} \%=7.2)$ obtained for all tested samples regardless of the type of interfering cytokine present.

\section{Reproducibility Tests}

The reproducibility tests for the developed IL-6 LFAs were carried out by assessing the performance of the test strips in three separate time intervals (1 day, 1 week, 1 month, $n=3$ for each) after preparation. Herein, two different concentrations (5 and $100 \mathrm{pg} /$ $\mathrm{mL}$ ) of IL- 6 were tested. These results indicate that the assay provides a reasonable reproducibility for colorimetric POC detection of IL-6 


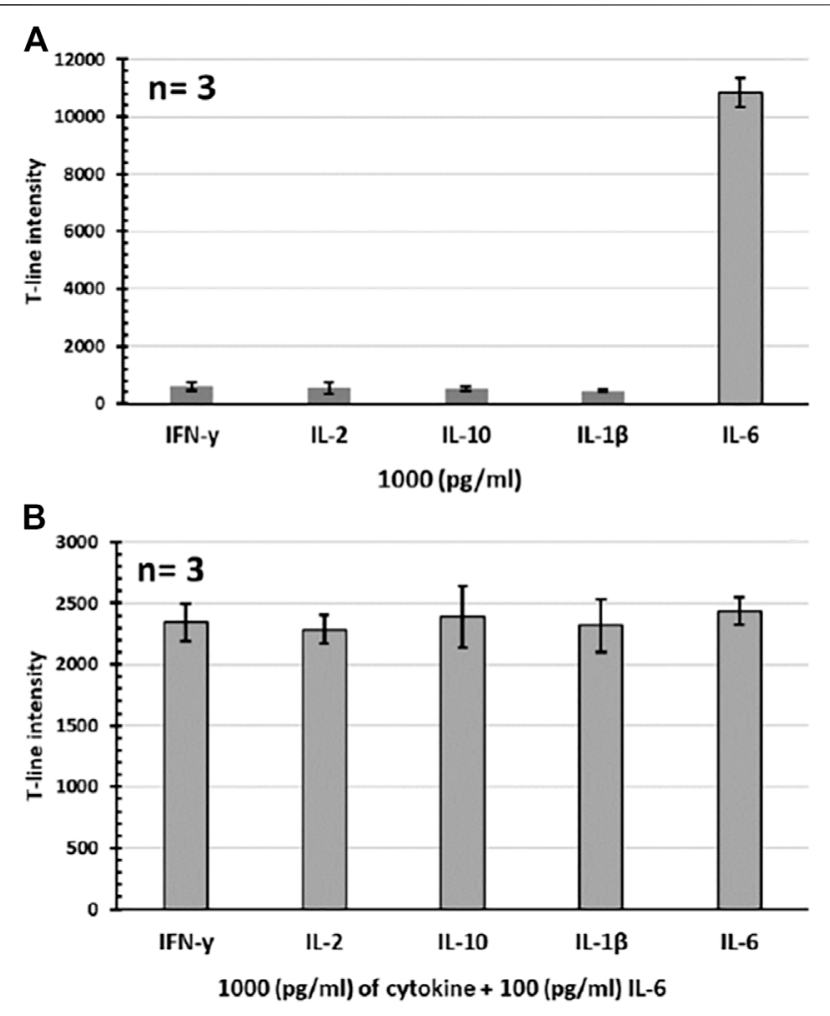

FIGURE 4 | Specificity tests for the developed IL-6 assay. (A) Individual cytokine samples. (B) IL-6 samples containing excess amount of individual cytokines. All tests were performed in $100 \%$ serum sample $(n=3)$.

TABLE 1 | Reproducibility test. LFA in three different time intervals (1 day, 1 week, and 1 month) and batch to batch test.

\begin{tabular}{lccccc}
\hline IL-6 pg/mL & \multicolumn{2}{c}{ Batch to batch test } & & \multicolumn{2}{c}{ Time intervals } \\
\cline { 2 - 3 } \cline { 5 - 6 } & \multicolumn{3}{c}{$\mathbf{3}$ batches, $\boldsymbol{n}=\mathbf{3}$ at each } & & 3 intervals, $\boldsymbol{n}=\mathbf{3}$ at each \\
\hline- & Mean $\pm \mathrm{SD}(\mathrm{T}$ intensity) & $\mathrm{CV} \%$ & & Mean $\pm \mathrm{SD}(\mathrm{T}$ intensity) & $\mathrm{CV} \%$ \\
5 & $594 \pm 75$ & 13.4 & & $450 \pm 86$ & 19.2 \\
100 & $2800 \pm 101$ & 3.6 & & $2380 \pm 304$ & 9.8 \\
\hline
\end{tabular}

analyte. The acquired signals in this regard are presented in Table $\mathbf{1 .}$ The batch-to-batch reproducibility was also assessed by preparing three individual batches of IL-6 LFA strips and running the assay for two different concentrations ( 5 and $100 \mathrm{pg} / \mathrm{mL}, n=3$ for each batch) of IL-6 samples. Similarly, results showed relatively consistent signal intensities obtained from different batches of test strips. The average measured signals for each tested concentration along with the calculated CV\% are presented in Table $\mathbf{1 .}$

\section{CONCLUSION}

In this work, a paper-based LFA was successfully developed for colorimetric point-of-care quantitative determination of IL-6 in biological samples. This assay incorporates silver amplification technique as a viable, low-cost, user-friendly, and efficient method for enhancing the obtained colorimetric signals from LFAs. The present assay allows detection of IL-6 in serum samples in the dynamic range of $5-1,000 \mathrm{pg} / \mathrm{mL}$ with a LOD of $5 \mathrm{pg} / \mathrm{mL}$. The specificity tests indicated the viability of the assay for detection of IL- 6 target analyte in real biological samples. The reproducibility tests also represent the reliability of the developed assay for detection of IL-6 in varying conditions. The fully colorimetric nature of the developed assay presents potentials for applicability of this assay in point-of-care detection of such a significant biomarker (i.e., IL-6) in low-resource settings. Future work remains to develop this system further for detection of IL-6 in whole blood samples by optimizing both the chemistry and design of the present assay. For instance, a sample preparation comportment (e.g., a plasma separation membrane) can be incorporated into the present LFA strips to filter out the red blood cells, enhancing the visibility of the colorimetric signals. Meanwhile, sensitivity of LFA can be further improved to meet the requirement of clinical detection by applying signal amplification technologies in POCT, such as CRISPR/Cas biosensing system (Liu et al., 2019; Dai et al., 2020; Lin et al., 2021; Shirshahi and Liu, 2021). Furthermore, the colorimetric feature of this assay allows further developments targeting smartphone-based POC detection of IL-6 and also other similar cytokines. Therefore, a smartphone-based readout system (i.e., a smartphone holder/light box) can be coupled with this assay to replace the herein implemented expensive LFA reader, enabling onsite, facile, and rapid image analysis for IL- 6 detection. Finally, this work can be extended for detection of other human cytokines such as IFN- $\gamma$, IL-2, IL-10, IL- $1 \beta$, et al.

\section{DATA AVAILABILITY STATEMENT}

The original contributions presented in the study are included in the article/Supplementary Material, further inquiries can be directed to the corresponding authors.

\section{AUTHOR CONTRIBUTIONS}

GL and JAS designed the project, managed the project, revised the project. MR performed the experiment, did the data analysis and drafted the manuscript. YW did data analysis and revised the manuscript.

\section{FUNDING}

This work was financially supported by Medimmune/ AstraZeneca Industry Fund, the ARC Future Fellowship (FT160100039), and the Chinese University of Hong Kong (Shenzhen) Presidential Fellowship, and the National Natural Science Foundation of China (Grant 2217040168). 


\section{REFERENCES}

Anfossi, L., Di Nardo, F., Giovannoli, C., Passini, C., and Baggiani, C. (2013). Increased Sensitivity of Lateral Flow Immunoassay for Ochratoxin A through Silver Enhancement. Anal. Bioanal. Chem. 405 (30), 9859-9867. doi:10.1007/ s00216-013-7428-6

Bahadır, E. B., and Sezgintürk, M. K. (2016). Lateral Flow Assays: Principles, Designs and Labels. Trac Trends Anal. Chem. 82, 286-306. doi:10.1016/j.trac.2016.06.006

Bishop, J. D., Hsieh, H. V., Gasperino, D. J., and Weigl, B. H. (2019). Sensitivity Enhancement in Lateral Flow Assays: a Systems Perspective. Lab. Chip 19 (15), 2486-2499. doi:10.1039/c9lc00104b

Borse, V. B., Konwar, A. N., Jayant, R. D., and Patil, P. O. (2020). Perspectives of Characterization and Bioconjugation of Gold Nanoparticles and Their Application in Lateral Flow Immunosensing. Drug Deliv. Transl. Res. 10 (4), 878-902. doi:10.1007/s13346-020-00771-y

Dai, Y., Wu, Y., Liu, G., and Gooding, J. J. (2020). CRISPR Mediated Biosensing toward Understanding Cellular Biology and Point-of-Care Diagnosis. Angew. Chem. 132, 20938-20950. doi:10.1002/ ange. 202005398

Han, H., Ma, Q., Li, C., Liu, R., Zhao, L., Wang, W., et al. (2020). Profiling Serum Cytokines in COVID-19 Patients Reveals IL-6 and IL-10 Are Disease Severity Predictors. Emerging Microbes \& Infections 9, 1123-1130. doi:10.1080/ 22221751.2020.1770129

Huang, D., Ying, H., Jiang, D., Liu, F., Tian, Y., Du, C., et al. (2020). Rapid and Sensitive Detection of Interleukin-6 in Serum via Time-Resolved Lateral Flow Immunoassay. Anal. Biochem. 588, 113468. doi:10.1016/ j.ab.2019.113468

Huang, L., Tian, S., Zhao, W., Liu, K., Ma, X., and Guo, J. (2020). Multiplexed Detection of Biomarkers in Lateral-Flow Immunoassays. Analyst 145 (8), 2828-2840. doi:10.1039/c9an02485a

Kany, S., Vollrath, J. T., and Relja, B. (2019). Cytokines in Inflammatory Disease. Ijms 20 (23), 6008. doi:10.3390/ijms20236008

Kumari, N., Dwarakanath, B. S., Das, A., and Bhatt, A. N. (2016). Role of Interleukin-6 in Cancer Progression and Therapeutic Resistance. Tumor Biol. 37 (9), 11553-11572. doi:10.1007/s13277-016-5098-7

Lin, X., Wang, G., Ma, L., and Liu, G. (2021). Study on Factors Affecting the Performance of a CRISPR/Cas-Assisted New Immunoassay: Detection of Salivary Insulin as an Example. Front. Bioeng. Biotechnol. 9, 752514, 1-12.

Liu, C., Chu, D., Kalantar-Zadeh, K., George, J., Young, H. A., and Liu, G. (2021). Cytokines: From Clinical Significance to Quantification. Adv. Sci. 8, 2004433. doi:10.1002/advs.202004433

Liu, G., Jiang, C., Lin, X., and Yang, Y. (2021). Point of Care Detection of Cytokines in Cytokine Storm Management and beyond: Significance and Challenges. View 2, 1-20. doi:10.1002/viw2.165

Liu, G., Zhang, K., Nadort, A., Hutchinson, M. R., and Goldys, E. M. (2017). Sensitive Cytokine Assay Based on Optical Fiber Allowing Localized and Spatially Resolved Detection of Interleukin-6. ACS Sens. 2 (2), 218-226. doi:10.1021/acssensors.6b00619

Liu, L., Yang, D., and Liu, G. (2019). Signal Amplification Strategies for PaperBased Analytical Devices. Biosens. Bioelectron. 136, 60-75. doi:10.1016/ j.bios.2019.04.043

Panferov, V. G., Safenkova, I. V., Byzova, N. A., Varitsev, Y. A., Zherdev, A. V., and Dzantiev, B. B. (2018). Silver-enhanced Lateral Flow Immunoassay for Highly-Sensitive Detection of Potato Leafroll Virus. Food Agric. Immunol. 29 (1), 445-457. doi:10.1080/ 09540105.2017.1401044

Panferov, V. G., Safenkova, I. V., Varitsev, Y. A., Drenova, N. V., Kornev, K. P., Zherdev, A. V., et al. (2016). Development of the Sensitive Lateral Flow Immunoassay with Silver Enhancement for the Detection of Ralstonia Solanacearum in Potato Tubers. Talanta 152, 521-530. doi:10.1016/ j.talanta.2016.02.050

Qi, M., Huang, J., Wei, H., Cao, C., Feng, S., Guo, Q., et al. (2017). Graphene Oxide Thin Film with Dual Function Integrated into a Nanosandwich Device for In
Vivo Monitoring of Interleukin-6. ACS Appl. Mater. Inter. 9 (48), 41659-41668. doi:10.1021/acsami.7b10753

Ragab, D., Salah Eldin, H., Taeimah, M., Khattab, R., and Salem, R. (20202020). The COVID-19 Cytokine Storm; what We Know So Far. Front. Immunol. 11, 1446. doi:10.3389/fimmu.2020.01446

Rodríguez, M. O., Covián, L. B., García, A. C., and Blanco-López, M. C. (2016). Silver and Gold Enhancement Methods for Lateral Flow Immunoassays. Talanta 148, 272-278. doi:10.1016/j.talanta.2015.10.068

Ruppert, C., Kaiser, L., Jacob, L. J., Laufer, S., Kohl, M., and Deigner, H. P. (2020). Duplex Shiny App Quantification of the Sepsis Biomarkers C-Reactive Protein and Interleukin-6 in a Fast Quantum Dot Labeled Lateral Flow Assay. J. Nanobiotechnology 18, 130. doi:10.1186/s12951-020-00688-1

Russell, C., Ward, A. C., Vezza, V., Hoskisson, P., Alcorn, D., Steenson, D. P., et al. (2019). Development of a Needle Shaped Microelectrode for Electrochemical Detection of the Sepsis Biomarker Interleukin-6 (IL-6) in Real Time. Biosens. Bioelectron. 126, 806-814. doi:10.1016/ j.bios.2018.11.053

Seruga, B., Zhang, H., Bernstein, L. J., and Tannock, I. F. (2008). Cytokines and Their Relationship to the Symptoms and Outcome of Cancer. Nat. Rev. Cancer 8 (11), 887-899. doi:10.1038/nrc2507

Shen, Z., Huang, J., Wei, H., Niu, H., Li, B., Li, R., et al. (2020). Validation of an In Vivo Electrochemical Immunosensing Platform for Simultaneous Detection of Multiple Cytokines in Parkinson's Disease Mice Model. Bioelectrochemistry 134, 107532. doi:10.1016/j.bioelechem.2020.107532

Shirshahi, V., and Liu, G. (2021). Enhancing the Analytical Performance of Paper Lateral Flow Assays: From Chemistry to Engineering. Trac Trends Anal. Chem. 136, 116200. doi:10.1016/j.trac.2021.116200

Stenken, J. A., and Poschenrieder, A. J. (2015). Bioanalytical Chemistry of Cytokines - A Review. Analytica Chim. Acta 853, 95-115. doi:10.1016/ j.aca.2014.10.009

Tanaka, T., Narazaki, M., and Kishimoto, T. (2014). IL-6 in Inflammation, Immunity, and Disease. Cold Spring Harbor Perspect. Biol. 6 (10), a016295. doi:10.1101/cshperspect.a016295

Wang, K., Qin, W., Hou, Y., Xiao, K., and Yan, W. (2016). The Application of Lateral Flow Immunoassay in point of Care Testing: a Review. Nano Biomed. Eng. 8 (3), 172-183. doi:10.5101/nbe.v8i3.p172-183

Wang, Y., Sun, J., Hou, Y., Zhang, C., Li, D., Li, H., et al. (2019). RETRACTED: A SERS-Based Lateral Flow Assay Biosensor for Quantitative and Ultrasensitive Detection of Interleukin-6 in Unprocessed Whole Blood. Biosens. Bioelectron. 141, 111432. doi:10.1016/j.bios.2019.111432

Ye, H., and Xia, X. (2018). Enhancing the Sensitivity of Colorimetric Lateral Flow Assay (CLFA) through Signal Amplification Techniques. J. Mater. Chem. B 6 (44), 7102-7111. doi:10.1039/c8tb01603h

Conflict of Interest: Authors YW and JAS were employed by the company AstraZeneca.

The remaining authors declare that the research was conducted in the absence of any commercial or financial relationships that could be construed as a potential conflict of interest.

Publisher's Note: All claims expressed in this article are solely those of the authors and do not necessarily represent those of their affiliated organizations, or those of the publisher, the editors and the reviewers. Any product that may be evaluated in this article, or claim that may be made by its manufacturer, is not guaranteed or endorsed by the publisher.

Copyright $\odot 2021$ Rahbar, Wu, Subramony and Liu. This is an open-access article distributed under the terms of the Creative Commons Attribution License (CC BY). The use, distribution or reproduction in other forums is permitted, provided the original author(s) and the copyright owner(s) are credited and that the original publication in this journal is cited, in accordance with accepted academic practice. No use, distribution or reproduction is permitted which does not comply with these terms. 